\title{
Diferença Ontológica, Pós-Fundacionismo e Exterioridade Constitutiva: reflexões sobre o fundamento autoestabelecido na Teoria do Discurso de Ernesto Laclau e Chantal Mouffe
}

\author{
Leonardo Monteiro Crespo de Almeida \\ Faculdade Imaculada Conceição do Recife/Universidade Federal de Pernambuco
}

\section{Introdução}

Uma das distinções de grande recorrência nas obras de Ernesto Laclau e Chantal Mouffe é entre o ôntico e o ontológico. Tendo uma origem marcadamente heideggeriana, os autores recorrem à mesma com o propósito de distinguir duas áreas de investigação específicas: uma referente às manifestações concretas dos fenômenos que perfazem o social, a exemplo dos desenhos institucionais, das mobilizações políticas concretas, enfim, naquilo que é imediatamente perceptível no espaço social, e uma outra que estabelece as condições dessas manifestações, sendo a realidade oculta e subjacente aos fenômenos.

Os dois domínios estabelecem entre si uma relação de entrelaçamento e interdependência, um remetendo ao outro. Em Hegemonia e Estratégia Socialista (1985) e nas obras subsequentes, Laclau e Mouffe desenvolveram a sua teorização com uma preocupação marcadamente ontológica ao ponto de reservarem para o domínio ôntico relativamente poucas considerações. Por isso, de certo modo, esta pesquisa concebe as pretensões teóricas de Laclau e Mouffe como a elaboração de uma ontologia política do social. O interesse dos autores acaba por repousar sob um conjunto de preocupações muito específicas, abstratas e um tanto quanto diversas daquelas dos cientistas políticos. Uma vez que sempre se enxergou como teórico político, Laclau manteve um distanciamento considerável de questões associadas à epistemologia e principalmente à metodologia da pesquisa tão decisivas para os cientistas políticos: a sua análise sempre fora direcionada aos processos políticos subjacentes nos quais os diversos sentidos do social são produzidos, organizados e deslocados ${ }^{1}$.

Interessava a Laclau e a Mouffe muito mais investigar as diversas maneiras pelas quais as identidades sociais negociavam o particular e o universal no processo de expansão e consolidação das suas demandas políticas do que a maneira como as instituições políticas deveriam se organizar para melhor atender a esses segmentos. Mesmo uma certa normatividade permanece elusiva, senão problemática, na obra dos autores, tanto a que escreveram em conjunto como as que compuseram sozinhos.

$\mathrm{Na}$ defesa que faz Mouffe do seu modelo de democracia agonística, caracterizada pelo pluralismo e pelo conflito entre adversários, por exemplo, o grau de abstração dos argumentos da autora é tão significativo que se torna desafiador vislumbrar as implicações normativas para fins de determinar possíveis déficits e avanços nas atuais formas de democracia em direção ao modelo que

\footnotetext{
${ }^{1}$ É de grande importância observar que, no contexto brasileiro das Ciência Política, a Escola de Teoria do Discurso de Pelotas, cuja produção em muito embasa várias das assertivas deste presente trabalho, produziu diversas análises empíricas tendo como embasamento teórico a própria teoria do discurso de Ernesto Laclau e Chantal Mouffe.
} 
propõe a autora. Na teorização do populismo desenvolvida por Laclau, especialmente em $A$ Razão Populista (2005), não somente se tematiza qualquer critério que poderia ser empregado para distinguir os regimes populistas existentes como, por exemplo, entre os que ampliam a participação social e os que são autoritários, como também permanece difícil vislumbrar elementos normativos que venham a caracterizar um modelo desejável de populismo e/ou estratégia política. Apesar das diferenças preocupações e marcos teóricos, em ambos os autores o cerne da preocupação teórica é ontológico.

O presente artigo se estrutura em três seções que possuem propósitos interligados, porém também relativamente independentes. A primeira seção busca esclarecer a diferença ontológica no desenvolvimento da teoria do discurso de Laclau e Mouffe. A diferença ontológica é tomada como referência para uma problematização do fundamento caracterizado em termos de identidade e permanência, tal como transcorreu ao longo da tradição metafísica ocidental. A segunda seção pretende situar o fundamento em termos de uma dinâmica de presença/ocultamento em Laclau/Mouffe ao mesmo tempo em que introduz a noção de exterioridade constitutiva com o propósito de apontar o caráter relacional, aberto e contingente das relações descritas pelas categorias empregadas pelos autores, a exemplo de discurso, prática articulatória e hegemonia.

Por fim, as duas noções centrais do artigo - fundamento e exterioridade constitutiva convergem na ideia de um fundamento autoestabelecido que estaria implícito na teoria do discurso. Nesta seção, então, a leitura já realizada por Daniel de Mendonça e Léo Peixoto Rodrigues (2006) sobre um possível diálogo entre Ernesto Laclau e Niklas Luhmann, serve para pensar uma ideia de fundamento centrada em redescrições contínuas operadas a partir do interior do próprio sistema que engloba aquele fundamento desde a própria teoria do discurso. Com isso, o artigo sustenta, em sua terceira seção, o discurso enquanto sistema discursivo caracterizado em uma autoprodução de sentido em meio a uma constituição relacional com o seu exterior, o campo de discursividade. Esse aspecto relacional, por sua vez, encontra-se presente na maneira como Laclau e Mouffe concebem a relação de antagonismo.

Em termos metodológicos, o artigo foi desenvolvido a partir de uma revisão de literatura marcada por dois eixos: o primeiro deles concerne ao universo teórico desenvolvido por Laclau e Mouffe, seja na obra em que escreveram juntos ou em suas obras particulares; o segundo eixo concerne à teoria dos sistemas e desdobramentos teóricos afins. Consideradas as prioridades teóricas deste trabalho, o segundo eixo foi menos explorado que o primeiro, sendo, porém, de grande relevância para se conceber teoricamente a noção central deste artigo, o fundamento autoestabelecido.

\section{Da Diferença Ontológica à distinção Político/Política na teoria de Laclau e Mouffe}

Em seu influente livro sobre a teoria política contemporânea, Post-Foundational Political Thought, Oliver Marchart (2007) ressalta a presença de uma reflexão ontológica em um contexto teórico no qual a própria ideia de fundamento é confrontada. Em Jean-Luc Nancy, Claude Lefort, Alain Badiou e, por fim, Ernesto Laclau, a incursão pela ontologia é crucial para a maneira como cada um dos autores conecta a própria reflexão política a contextos teóricos nos quais a fundamentação do social já não reside em uma substância determinada e perene, nem em significantes transcendentais que, por si só, subtraem-se ao questionamento. 
Neste panorama, o social carece de um sentido último e, por isso mesmo, a sua organização é marcada por uma oscilação contínua na qual os conflitos entre formas diversas de significação do social jamais serão solucionados em definitivo. Se o social carece de uma essência na qual as diversas formas de narrativa poderiam se ancorar, tornando-a também um eixo no qual as narrativas podem recorrer para criticarem umas às outras, o sentido do fundamento deixa de ser o de uma presença absoluta a partir de si mesma, o significante transcendental por excelência, para se configurar em uma dinâmica de presença e ausência.

Ao invés de dissolver qualquer consideração em torno da ideia de fundamento, essa dinâmica desfaz a ideia de uma presença que se impõe como identidade de si mesma para reposicioná-la em função de sua ausência: ao invés de amplamente determinada pelo princípio da identidade $(A=A)$, a presença concebida deste modo é elusiva e sempre precária. Marchart ressalta este ponto da seguinte forma:

Ao sustentar que o fundamento permanece presente em sua ausência, nós queremos ressaltar o fato de que a ausência do fundamento não significa simplesmente que o processo de fundamentação foi suspenso. Muito pelo contrário, o fundamento permanece, de certo modo, 'operativo' enquanto fundamento apenas por conta de sua própria ausência, sendo por isso que a ausência do fundamento não pode ser concebida como um cancelamento 'total', como 'mera' ausência (Marchart, 2007, p. $18)^{2}$.

Um fundamento cuja presença é concebida nesses termos será instável e em constante redefinição. É daqui que surge e se desenvolve a influência marcadamente heideggeriana que envolverá a teorização política dos autores elencados por Marchart. É no filósofo alemão que a noção de Abgrund, de um fundamento translúcido, "sem chão", mas que permanece existindo como um espaço cuja presença não se deixa apreender por um sentido decisivo (Marchart, 2007, p. 18 e ss). Em síntese, na concepção heideggeriana, a função do fundamento é mantida, mas o seu preenchimento se faz através de uma dinâmica marcada por um esvaziamento contínuo e, por isso mesmo, pela impossibilidade do seu esgotamento.

O fundamento é o marcador de uma ausência inapreensível e inesgotável situada no centro do social. À atividade política, em sua acepção ontológica, caberá trazer à tona esse processo constante de retraimento e diferenciação que vai constituir a estrutura de sentido subjacente ao espaço social. É nesse ponto em que preciso atentar para a maneira como Heidegger situa a distinção entre o ôntico e o ontológico, que se encontra no cerne da ontologia política de Laclau e Mouffe.

Uma forma sucinta de abordagem da diferença ontológica (ôntico/ontológico) reside em situar o ontológico como a condição de possibilidade das manifestações empíricas dos entes, estas estando compreendidas na dimensão ôntica (Heidegger, 2005a, p. 40 e ss). Estabelece-se desta maneira uma forma de paralelismo através da diferenciação ontológica: o ontológico se associa ao ser enquanto o ôntico está associado ao ente. Por isso o dasein é onticamente o mais próximo de nós, já que enquanto seres humanos somos também dasein, mas ontologicamente o mais distante. Isso ocorre porque todo

\footnotetext{
${ }^{2}$ No original: "In claiming that the ground remains present in its absence, we underline the fact that the ground's absence does not imply that the process of grounding comes to a halt. On the contrary, the ground remains, to some extent, 'operative' as ground only on the basis of its very absence, which is why the absence of the ground must not be envisaged as 'total' cancellation, as 'mere' absence".
} 
o conhecimento que acabamos dispondo sobre nós e os outros remetem, no fundo, sempre a um conjunto de propriedades e características associadas ao ente, portanto, ao ôntico.

Isso significa que o envolvimento cotidiano do dasein com os entes circundantes acaba o afastando de considerar a sua própria estrutura existencial (Heidegger, 2005a, p. 38 e ss). Desenvolvendo um leve paralelo com a teorização política, pode-se dizer que a preocupação com as instituições, os partidos e demais atores políticos que compõem a dinâmica institucional das democracias liberais contemporâneas tendem a desconsiderar a dimensão ontológica da política, ou seja, as condições de existência dos entes que são objeto da investigação teórica (Mouffe, 2005, p. 9 e ss).

Essa relação entre ser e ente, entre o ôntico e o ontológico, cerne da diferença ontológica heideggeriana é transposta para o âmbito de teorização política através de uma outra distinção, entre o político e a política (Mouffe, 2005, p. 8-9). De maneiras diversas, cada um dos autores analisados por Marchart operam um corte bem definido entre as entidades concretas que compõem o espaço usual da prática política e as condições subjacentes por meio das quais essas entidades podem existir e o sentido do social ser fixado. Uma ontologia política precisa preliminarmente destacar os conflitos entre forças que de diversas maneiras terminam concorrendo para a formação da estrutura social, ainda que essas forças não necessariamente se deixem apreender pelos limites estabelecidos pelas instituições.

Encontrando-se no cerne de uma forma de conceber a ontologia política, a distinção político/política nomeia o primeiro capítulo de Sobre o Político de Chantal Mouffe (2005). A influência heideggeriana não é só explicitamente assumida, como é fundamental para a demarcação entre os domínios da ciência política e os da teoria política: constrói-se, desta maneira, dois campos de investigação com objetos e formas de abordagem marcadamente diferentes (Mouffe, 2005, p. 8 e ss). A questão se torna também epistemológica uma vez que as pretensões científicas das ciências políticas a conduziram, conforme Mouffe, a investigar tão somente os fenômenos empiricamente determinados, cabendo à teoria política a determinação de uma função operativa última da política, ou seja, a sua essência, transcendendo os limites do empírico (Mouffe, 2005, p. 8-9).

Em síntese, Mouffe opera uma distinção pontual entre o espaço da política convencional, empiricamente analisável, da forma com que a própria sociedade é concebida, as já mencionadas condições subjacentes aos fenômenos que constituem a política convencional. No panorama histórico da teoria política, duas perspectivas acabam sendo recorrentes quanto à natureza do político: a primeira, discernível em Hannah Arendt (2016), concebe o político como espaço de liberdade e deliberação pública na qual os diferentes atores sociais, juntos, constroem o espaço social público no qual vão concretizar os seus projetos existenciais particulares; outra concepção, aquela defendida pela própria Mouffe, concebe o político como espaço de lutas de poder, conflito e antagonismo (Mouffe, 2005, p. 9).

Uma vez que a autora desloca o antagonismo e o conflito para o campo do político, ela atribui a ambos uma dimensão ontológica que os torna fundamentais para a organização e reprodução do social (Mouffe, 2005, p. 9; Mouffe, 1993, p. 3 e ss). Os termos passam a possuir dois sentidos muito específicos e que em nenhum momento se confundem ao lidarem com dimensões distintas do social: o conflito em termos ônticos, como decorrente de um conflito partidário ou entre movimentos sociais, pode ser solucionados através dos mecanismos institucionais estabelecidos; o conflito em sua acepção ontológica, por sua vez, carece de solução por essa via. 
Este é um dos cernes da reflexão que Mouffe pretende articular: o tipo de conflito apresentado pelo político exige uma decisão excludente que transcendente avaliações estritamente técnicas de uma situação. Não se trata da solução mais eficiente ou menos custosa, mas de se optar por uma dentre as diversas perspectivas conflitantes sobre uma dada questão. A autora escreve:

O ponto de partida da minha investigação é nossa presente incapacidade de conceber os problemas de nossa sociedade em termos políticos. O que eu quero dizer é que as questões políticas não são apenas assuntos técnicos a serem solucionados pelos especialistas. Questões que são propriamente políticas sempre envolvem decisões que requerem que nós optemos por uma entre as alternativas conflitantes (Mouffe, 2005 , p. 10) ${ }^{3}$.

Embora a sua reflexão em obras como Sobre o Político seja conduzida com os aspectos mais usuais das democracias contemporâneas, estando por isso mesmo circunscritos ao domínio ôntico, o núcleo de sua reflexão permanece sendo ontológico uma vez que aquilo que está em jogo é a problematização de uma abordagem estritamente técnica da política, como a passagem citada aponta (Mouffe, 2005, p. 9 e ss). Retornar a uma reflexão ontológica sobre o político por uma via heideggeriana permite a Mouffe colocar em questão não apenas os desenhos institucionais que envolvem - e mesmo possibilitam - o pluralismo e a intermediação dos conflitos em sociedades complexas, como também a busca por um significado mais profundo - e por que não mais originário? - acerca do político, logo também das bases do social. Em síntese, mesmo que implicitamente, podese dizer que o ontológico, na teorização de Mouffe, surge como um campo que envolve os fenômenos empíricos sem, contudo, ser ele mesmo enunciado, aparente (Mouffe, 2005, p. 9 e ss).

Esse processo, porém, traduz uma certa bilateralidade que não é prontamente discernível nas considerações de Mouffe, especialmente em Sobre o Político, porque o ontológico não se constitui no cerne de sua teorização política particular, dentre outras razões. Por bilateralidade aponta-se a maneira como os dois polos se transformam através de interações contínuas, ou seja, não apenas o ontológico fornece as condições de objetividade do ôntico, mas modificações que ocorrem neste plano, tendem a reorganizar o ontológico. Em síntese, a bilateralidade mencionada neste parágrafo significa que um domínio não se sobrepõe e determina o outro: pelo contrário, a relação estabelecida entre eles é mutualmente constitutiva (Laclau e Mouffe, 1985, p. x e ss; Mouffe, 2005, p. 9 e ss).

Em Hegemonia e Estratégia Socialista, publicado vinte anos antes de Sobre o Político, já se encontra uma formulação da diferença ontológica heideggeriana, destacando a dinâmica existente entre os dois eixos (Laclau e Mouffe, 1985, p. 111 e ss). Conceber o ontológico em termos de um campo, como fora feito no parágrafo anterior, remete a uma ideia de extensão, associada também ao transcendental kantiano: o campo como espaço que estabelece as condições de pensamento e, de antemão, também os seus limites. Escrevem os autores:

Qualquer mudança substancial no conteúdo ôntico de um campo de pesquisa leva também a um novo paradigma ontológico. Althusser frequentemente dizia que por

\footnotetext{
${ }^{3}$ No original: "The point of departure of my enquiry is our current inability to envisage the problems facing our societies in a political way. What I mean by that is that political questions are not mere technical issues to be solved by experts. Properly political questions always involve decisions which require us to make a choice between conflicting alternatives".
} 
trás da filosofia de Platão existia a matemática grega; por trás do racionalismo do século dezessete, a física galileana; e por trás da filosofia de Kant, a teoria newtoniana. Estabelecendo o argumento em termos transcendentais: uma questão estritamente ontológica pergunta como as entidades passaram a existir para que a objetividade de um campo particular seja possível. Existe o processo de interação mútua entre a incorporação de novos campos de objetos e as categorias ontológicas gerais que governam, em um dado momento, o que é pensável a partir do campo geral de objetividade (Laclau e Mouffe, 1985, p. x) ${ }^{4}$.

A passagem mostra com certa nitidez as bases gerais de uma ontologia política. A principal pretensão reside em esclarecer as estruturas e condições associadas ao político dotadas de certa fixação, o que aparece em Hegemonia e Estratégia Socialista através das relações diversas estabelecidas entre os conceitos que os autores desenvolvem (Laclau e Mouffe, 1985, p. 12). Discurso, hegemonia, articulação, cadeias de equivalência, antagonismo, dentre outros, não são noções a serem debatidas ou confrontadas nos espaços empiricamente situados da arena política, antes constituem as condições pelas quais o debate e o conflito podem ocorrer em meio à superfície do social.

Trazendo para a discussão estabelecida por Mouffe em Sobre o Político, pode-se dizer que certas transformações ônticas nas sociedades europeias, como o colapso das nações socialistas e a difusão de concepções "pós-ideológicas" como forma de abordagem dos impasses políticos, tendem a reformular ou introduzir novas referências no plano ontológico (Mouffe, 2005, p. 48 e ss; Laclau e Mouffe, 1985, p. 1 e ss). Essa, aliás, é uma das linhas centrais de sua argumentação na obra mencionada: uma investigação ontológica é importante porque o "pós-ideológico" traz consigo uma desconsideração do conflito como constitutivo do social, ou seja, ela o desconsidera em termos ontológicos.

O cerne do "pós-ideológico" é o consenso e através dele a possibilidade de superação do antagonismo através da fixação de parâmetros normativos que, ao menos em tese, eliminaria a decisão política por uma das perspectivas conflitantes. Ainda em Sobre o Político, Mouffe escreve:

Um ponto central na abordagem de Schmitt é o de que, ao mostrar que cada consenso é baseado em atos de exclusão, revela-se a impossibilidade de um consenso 'racional' inteiramente inclusivo. Agora, como eu menciono, próximo ao individualismo, uma outra característica crucial para boa parte do pensamento liberal é a crença racionalista na disponibilidade de um consenso universal ancorado na razão. Não é de se espantar que o político constitua o seu ponto cego. O político não pode ser apreendido pelo racionalismo liberal pela simples razão que cada forma

\footnotetext{
${ }^{4}$ No original: "Any substantial change in the ontic content of a field of research leads also to a new ontological paradigm. Althusser used to say that behind Plato's philosophy, there was Greek mathematics; behind seventeenth-century rationalism, Galilean physics; and behind Kant's philosophy, Newtonian theory. To put the argument in a transcendental fashion: the strictly ontological question asks how entities have to be, so that the objectivity of a particular field is possible. There is a process of mutual feedback between the incorporation of a new fields of objects and the general ontological categories governing, at a certain time, what is thinkable within the general field of objectivity".
} 
consistente de racionalismo exige a negação da irredutibilidade do antagonismo (Mouffe, 2005, p. 11-12).

Chantal Mouffe recorre a Carl Schmitt não apenas para desenvolver uma caracterização do político em termos de antagonismo, como também para fortalecer a ideia de um social que é continuamente deslocado (Mouffe, 1993, p. 118 e ss; Mouffe, 2005, p. 14 e ss). Isso significa que qualquer formação de sentido abrangente do social ocorre através da exclusão e, por isso mesmo, somente pode ser parcial e precariamente fixada. Em Hegemonia e Estratégia Socialista, os autores reforçam a impossibilidade da objetividade, ou seja, o sentido de uma determinada formação social não repousa em si mesmo, mas na diferenciação que estabelece com o seu exterior em termos do que fora excluído (Laclau e Mouffe, 1985, p. 109 e ss).

Essa relação entre deslocamento, antagonismo e exclusão também pode ser discernida na obra de Ernesto Laclau sem, contudo, nenhuma influência direta, ou mesmo indireta, de Carl Schmitt ou da preocupação implicitamente normativa que conduz Mouffe a uma crítica ao pós-político e ao racionalismo liberal. Em New Reflections on the Revolution of Our Time (1990), The Making of Political Identities (1994), Emancipation(s) (1996) ou A Razão Populista (2005), por exemplo, a formação das identidades, bem como o desenvolvimento analítico de noções como representação política e de emancipação, são perpassadas por uma tensão na qual a realização delas existe em função de um exterior que também não se deixa ser apreendido integralmente.

Destaquemos a dinâmica da lógica populista: uma de suas condições é a existência de uma formação discursiva capaz de tornar equivalente os diversos embates sociais na construção do povo enquanto sujeito coletivo. A constituição do povo, porém, depende de uma tensão antagônica e persistente entre ele, o povo, e o que surge como obstáculo à concretização das diversas pretensões populares: o sistema, a elite parasitária e rentista, etc. Uma vez que, na acepção laclauniana, o povo carece de uma essência em termos de atributos que lhe seriam persistentes, a sua existência ocorre em função da contraposição que permitirá a formação - e também manutenção - das cadeias de equivalência (Laclau, 2005, p. 77 e ss).

Dada a sua importância para a diferença ontológica no horizonte da teoria política de Laclau e Mouffe, a noção de exterior constitutivo precisa ser mais desenvolvida, o que será feito na seção seguinte.

\section{Diferença ontológica e exterioridade constitutiva}

Se a apropriação de Laclau e Mouffe da diferença ontológica heideggeriana redefine a ideia de fundamento tal como se encontra presente na tradição metafísica, o fundamento é concebido em termos de uma ausência incontornável no centro da teoria política dos autores. A relação entre presença/ausência ou desvelamento/ocultamento formaria a condição sem a qual a sutura do universal e do particular operada pela hegemonia perderia todo o seu propósito: se o fundamento pode ser apreendido em termos de uma presença que se faz idêntica a si mesma, ele acaba por representar

\footnotetext{
${ }^{5}$ No original: "A key point of Schmitt's approach is that, by showing that every consensus is based on acts of exclusion, it reveals the impossibility of a fully inclusive 'rational' consensus. Now, as I indicated, next to individualism, the other central trait of most liberal thought is the rationalist belief in the availability of a universal consensus based on reason. It is therefore no wonder that the political constitutes its blind spot. The political cannot be grasped by liberal rationalism for the simple reason that every consistent rationalism requires negating the irreducibility of antagonism".
} 
também a referência normativa e mesmo epistêmica para toda e qualquer formação discursiva que tome o social como seu objeto (Laclau e Mouffe, 1985, p. 143 e ss; Laclau, 1996, p. 28 e ss). Também se o fundamento pudesse ser apreendido tal como fora mencionado, seria igualmente viável retornar a uma concepção de sujeito histórico que representa os interesses e necessidades universais de toda humanidade, a exemplo da classe operária na dinâmica histórica apresentada pelo marxismo.

Essa possibilidade só é factível se o fundamento do social for marcado por uma essência no sentido de um conjunto de propriedades definitivas e perene. A hegemonia é a tentativa, sempre incompleta, de apreensão dessa totalidade social: a condição de possibilidade para que haja hegemonia repousa na impossibilidade mesma do social (Laclau e Mouffe, 1985, p. 111; Laclau, 2000, p. 185 e ss). Dito de outro modo, é porque o social não pode ser definitivamente apreendido, que as tentativas de determinação do seu sentido através das formas hegemônicas persistirão: a composição de cadeias de equivalência antagônicas reflete as diferentes formas de negociação do sentido do social (Laclau e Mouffe, 1985, p. 141 e ss; Laclau, 1990, p. 20 e ss).

Em Post-Foundational Political Thought, Marchart observa que, no tocante a uma posição associada à disponibilidade do fundamento, duas são as vias de desenvolvimento desta questão, sendo uma delas um retorno ao fundacionismo tal como presente na tradição metafísica ocidental. Ele escreve:

\begin{abstract}
Deste modo nós poderemos fazer apenas duas coisas: ou desistimos do nosso ponto de partida e retornamos a uma posição fundacionalista, ou aguentamos as consequências e damos um passo final em aceitar a impossibilidade de um 'fundamento' que apreenda todas as fundamentações contingentes - isso se nós nos mantivermos como anti-fundacionalistas - e deste modo o seu status será mais forte do que o status de cada uma dessas fundamentações: a impossibilidade do fundamento é uma impossibilidade necessária. Ela descreve a ausência necessária de um fundamento último. Uma ausência que, diga-se de passagem, é produtiva, ao invés de meramente negativa (Marchart, 2007, p. 18) ${ }^{6}$.
\end{abstract}

Essa ausência produtiva mencionada por Marchart, também pode ser vislumbrada na ontologia de Heidegger, é concebida em termos de um deferimento contínuo que expressa a impossibilidade de uma constituição definitiva de uma dada estrutura de sentido. O cerne dessa linha de argumentação já fora apresentado por Jacques Derrida em vários dos seus artigos escritos na década de sessenta e setenta, sendo o mais famoso deles "Estrutura, signo e jogo no discurso das ciências humanas" (Derrida, 1978).

Se em Hegemonia e Estratégia Socialista a presença da desconstrução é decisiva, permanecendo forte mesmo nas obras subsequentes, em grande parte isso pode ser creditado à maneira como Derrida, segundo o próprio Marchart, subverte as bases do fundacionalismo através do seu embate com a concepção de estrutura centrada então em voga por conta do Estruturalismo (Laclau e Mouffe, 1985, p. 111-112). A consideração estabelecida por Derrida neste ponto tornou-se

\footnotetext{
${ }^{6}$ No original: "Thus we can only do two things: either we give up our starting point and return to a foundationalist stance, or we bear the consequences and take the final step of accepting that the impossibility of becoming 'ground' must hold for all contingent foundations - if one wants to remain anti-foundationalist - and so its status is stronger than the status of each of those plural foundations: the impossibility of ground is a necessary impossibility. It describes the necessary absence of an ultimate ground. An absence which, as must be noted, is a productive absence, and not merely negative".
} 
amplamente conhecida e será retomada por Laclau e Mouffe em diferentes momentos de suas obras: a noção de jogo exige um fundamento último, imóvel e sólido, que, por sua vez, subtraia-se ao próprio jogo de que é condição (Laclau e Mouffe, 1985, p. 112 e ss).

Em termos metafísicos, como já fora mesmo apontado, o que se tem aqui é o significante transcendental que, ao longo da tradição metafísica, vai se manifestar em termos como eidos, arché, telos, energia, ousia, Deus, ser humano, dentre outros. Ao mesmo tempo em que esses termos já trazem consigo as implicações mencionadas por Derrida, há uma certa dimensão histórica na qual essa desestabilização do fundacionalismo vai operar, e que o filósofo argelino associa aos nomes de Nietzsche, Freud e Heidegger. Nessas três personalidades, que emergem no final do século dezenove e início do século vinte, podem-se encontrar formulações nas quais as formas de fundamentação transcendentes presentes na tradição metafísica são desestabilizadas (Laclau e Mouffe, 1985, p. 111112; Laclau, 1990, p. 17 e ss).

As circunstâncias históricas, especialmente no que tange às formas e práticas de mobilização política nas últimas décadas do século passado, também pressionam Laclau e Mouffe a repensarem as suas bases teóricas. Hegemonia e Estratégia Socialista inicia com um prefácio no qual os autores traçam diagnóstico de uma crise da esquerda não somente teórica, como estratégica (Laclau e Mouffe, 1985, p. 1 e ss; Laclau, 1990, p. xi e ss). Ao mesmo tempo em que o cerne dessa crise traz consigo uma dimensão inequivocamente histórica, havendo menções diretas à dissolução da URSS e à inabilidade das formas de organização usuais da esquerda em darem conta da emergência dos novos movimentos sociais e à especificidade das suas demandas.

Em paralelo a esse panorama, tem-se a constatação de que o proletário já não pode mais desempenhar o papel histórico de um sujeito político universal que, em sua luta, representa também a luta da humanidade pela sua própria emancipação. O sentido mesmo de humanidade, aliás, esvaziase nesse período.

O conceito de hegemonia atua, no desenvolvimento dessa obra e das outras que lhe foram subsequentes, como um ponto de convergência no qual o teórico e o estratégico tendem a confluir. A crise de um sujeito político universal se expressa em uma desconsideração do universal cujo preço para a esquerda, principalmente em termos estratégicos, será o de uma fragmentação constante que resultará, por sua vez, em um culto das particularidades de cada movimento.

Em termos estritamente teóricos, o puro particularismo é inviável: a rejeição ao universal é também a rejeição da transcendência que envolve a linguagem na qual será formulada a própria demanda. Uma linguagem estritamente particular e específica é insuscetível de transmitir qualquer conteúdo. Como Hegel observará na Fenomenologia do Espírito, a enunciação do mais particular, do aqui e agora, é também universal (Hegel, 2003, p. 85 e ss). As páginas iniciais de Hegemonia e Estratégia Socialista são, em parte, dedicadas a uma desconstrução da ideia de classe como uma totalidade uniforme composta por elementos homogêneos. Diversos foram os esforços para se determinar qual seria a organização da classe operária, os seus interesses e necessidades, o projeto revolucionário e as estratégias disponíveis para a sua consolidação.

São todas preocupações que se desenvolvem através da convergência entre uma dupla concepção essencialista do conceito de classe e de universal. Considerável parte do primeiro capítulo de Hegemonia e Estratégia Socialista é dedicado a mostrar que, na realidade, a classe operária jamais se constituiu na unidade estabelecida pela teoria: a disparidade de remuneração, de condições e oportunidades, assim como a fragmentação interna em termos de estratégia e mobilização política 
(Laclau e Mouffe, 1985, p. 8 e ss). Ainda que essa dispersão não fosse tão abrangente e radical como a que será observada nas últimas décadas do século vinte, a unidade política da esquerda, seja em termos de partido ou classe, nunca fora dada a priori, necessitando sempre ser construída em meio às diferentes circunstâncias.

Conforme observado, a hegemonia atende por essa lógica de construção de subjetividades coletivas através da articulação contingente de elementos distintos em composições relativamente estáveis (Laclau e Mouffe, 1985, p. 153 e ss). Nisso surge como uma resposta que não se limita apenas a endereçar a crise teórica, nem os seus desdobramentos práticos, mas desenvolver uma ontologia política ancorada sob um vazio produtivo e evanescente, perfeitamente ajustado ao que pretende o conceito de hegemonia tal como os autores o desenvolvem.

Se a formação da hegemonia repousa sob a construção de cadeias de equivalência em um contexto no qual o fundamento do social não pode ser inteiramente apreendido, a exterioridade é um aspecto constitutivo da hegemonia. A exteriorização é o inapreensível que se desenvolve a partir do momento em que é instaurada a relação de antagonismo. Entretanto, pode-se dizer que essa noção de exterioridade não se limita, nem se circunscreve, à polarização decorrente da mencionada relação (Laclau e Zac, 1994, p. 13 e ss). Ao menos dois pontos baseados em uma noção explícita de exterioridade podem ser discernidos na teoria dos autores: o primeiro, já tratado ao longo deste trabalho, reside na noção de fundamento que eles apreendem, de certo modo, da ontologia heideggeriana; o segundo diz respeito à relação entre discurso e campo de discursividade (Laclau e Mouffe, 1985, p. 111; Mendonça e Rodrigues, 2006, p. 93 e ss).

Um fundamento concebido em termos de uma dinâmica de presença/ocultação, ou seja, elusivo, vai continuamente subtrair-se a qualquer tentativa de posicioná-lo como algo do qual se pode deduzir - e fundar - uma estrutura de sentido definitiva, a exemplo da própria ordem social. Uma ordem estabelecida através da concepção de fundamento mencionada será sempre marcada por uma dose de precariedade que revela a contingência do seu processo de emergência, assim como a fragilidade de sua constituição.

A exterioridade presente no fundamento será, por sua vez, interna à colocação mesma da estrutura de significação, ou seja, uma estrutura estabelecida será sempre marcada por um vazio constitutivo (Laclau e Zac, 1994, p. 12 e ss). Com certa liberalidade pode se conceber, em termos ônticos, esse vazio como associado à dissolução dos marcadores de certeza que Claude Lefort verá como ponto central na gênese da democracia moderna (Laclau e Mouffe, 1985, p. 155). Uma vez que não se deixa apreender em definitivo, as formações hegemônicas só podem se suceder umas às outras, e cada uma delas tende a formar e a fixar temporariamente o sentido do social na medida em que exclui e/ou desconsidera elementos que não lhe são compatíveis e que obstruem a sua formação, tal como ocorre na relação de antagonismo.

O conceito de discurso, na teoria de Laclau e Mouffe, é também marcado por uma dinâmica semelhante. Em Hegemonia e Estratégia Socialista, por exemplo, o discurso surge através de uma delimitação ante ao que os autores nomeiam campo de discursividade (Laclau e Mouffe, 1985, p. 111 e ss). Então, somente quando existe uma delimitação entre o dentro (o discurso que estabelece o sentido) e o fora (o campo de discursividade, marcado por um excesso de significação) é que poderá haver a formação discursiva propriamente dita.

A princípio pode-se dizer, ainda seguindo o desenvolvimento conceitual proposto em Hegemonia e Estratégia Socialista, que a transição de elementos para momentos, levando a passagem 
de uma lógica da diferença para uma da equivalência, é que seria caracterizadora do discurso, mas isso é tentar compreendê-lo a partir do que ele tende a incluir, ou seja, de sua configuração interna (Laclau e Mouffe, 1985, p. 127). No entanto, se uma formação discursiva é constituída através de uma delimitação que opera perante o campo de discursividade, então o próprio da formação discursiva não pode residir em si mesma, mas naquilo que exclui e que lhe é incompatível. Pode-se aqui pensar numa formulação que, soando paradoxal, ainda assim define com precisão o que é estabelecido em Hegemonia e Estratégia Socialista e nas obras posteriores: o dentro é constituído e definido pelo fora, o fundamento da presença reside no vazio que lhe é interior (Laclau e Zac, 1994, p. 15 e ss).

Se a política envolve a construção de narrativas que significam, organizam e propõem condições que permitem - ou obstruem - os caminhos do pensamento, formulações ontológicas podem trazer ressonâncias significativas para a epistemologia social, muito embora este último domínio não tenha interessado tanto a Laclau e Mouffe. Ainda assim, as proximidades entre o que os autores propõem em termos conceituais e certas posições epistemológicas mais recentes merecem uma análise mais apurada, sobretudo para desenvolver com mais atenção as implicações da posição ontológica adotada pelos autores. Adiante será, agora, discutido o conceito de exterioridade constitutiva em justaposição a pós-fundacionalismo apontado por Marchart.

\section{Fundamento autoestabelecido e sistemas discursivos: as implicações epistemológicas da teoria do discurso}

A noção de exterioridade constitutiva é o elo que associa o pós-fundacionismo, tal como Marchart o aborda, dos vários desdobramentos associados epistemológicos contemporâneos, tais como os trabalhados de Humberto Maturana e Francisco Varela, sobretudo no que se refere ao conceito de autopoiesis (Rodrigues, 2006, p. 59 e ss). Muito embora essa corrente definitivamente não esteja diretamente associada à diferença ontológica tal como Heidegger a situa, a maneira pela qual não só Laclau e Mouffe, como o próprio Marchart, posicionam a diferença entre o ôntico e o ontológico a partir de um fundamento que já não opera como um significante transcendental, ou seja, como uma estrutura fechada e definida a partir de si mesma, em nosso entendimento tendem a permitir essa aproximação.

No artigo Laclau e Luhmann: um diálogo possível, constante no livro de Daniel de Mendonça e Léo Peixoto Rodrigues (2006), os autores elencam uma série de convergências que acabam por unir teoria do discurso e teoria dos sistemas. Mesmo considerando as amplas diferenças que existem entre as duas teorias, o que já se inicia a partir das pretensões teóricas que as norteiam, elas tendem a se aproximar não só em termos de um pós-fundacionismo, como também de certos traços construtivistas que acabam por esboçar em determinados pontos. Ainda que sejam noções bem distintas, pósfundacionismo e construtivismo se encontram articuladas no desdobramento de ambas as teorias. Escrevem os autores:

Um aspecto fundamental que norteia a nossa análise comparativa é que ambos os autores, no desenvolvimento de suas teorias, estão inscritos numa perspectiva sistêmica, cujas características gerais são: (a) sistema fechado: porque existe uma circularidade necessária e suficiente entre seus elementos para que toda e qualquer operacionalização com vistas à manutenção do próprio sistema se realize a partir dos seus próprios componentes; (b) diferenciação sistema-entorno: porque o sistema 
apresenta limites (fronteiras ou bordas) que o diferencia do meio ambiente (entorno) em que está inserido, acoplado; (c) sistema autorreferente (autopoiético): porque produz e reproduz a si próprio de forma semântica, o que significa afirmar que responde às transformações do meio ambiente que está acoplado, a partir de seus próprios componentes operacionais, com vista a sua manutenção; (d) vinculam-se a uma teoria da diferença (Mendonça e Rodrigues, 2006, p. 88 e ss).

A citação acima elenca convergências através da linguagem da teoria dos sistemas, o que por sua vez não torna imediatamente claro como esses pontos podem ser encontrados na teoria do discurso de Laclau e Mouffe, principalmente porque trazem uma carga epistemológica que em nenhum momento tende a integrar o primeiro plano na teorização proposta por eles. Vejamos, porém, como abordar a própria teoria do discurso desde uma perspectiva sistêmica e qual o ganho teórico e analítico dessa perspectiva para se pensar o pós-fundacionismo.

Um traço decisivo na noção de autopoiesis reside na autoconstrução de um organismo, ou, mais abstratamente, um sistema. Tal como ocorre na determinação da hegemonia, das cadeias de equivalência ou mesmo de um discurso, o sistema só pode existir através de uma delimitação com o seu entorno ou, na acepção dos autores, o meio ambiente. Embora Laclau e Mouffe não façam menções a essa noção, muitas outras trabalhadas por ele acabam exercendo função semelhante, conforme mencionamos: o campo de discursividade no tocante ao discurso e a contra-hegemonia presente na relação de antagonismo instaurada pela hegemonia, manifestam formas de exterioridade que constituem as duas noções em evidência, o discurso e a hegemonia.

$\mathrm{Na}$ constituição das duas noções, seja na emergência de uma formação discursiva via práticas articulatórias ou na fixação de uma posição hegemônica, constroem e reconstroem a partir de si mesmo os elementos necessários para a manutenção das suas formações. Em Hegemonia e Estratégia Socialista, por exemplo, a articulação é um processo que permite a emergência de uma nova posição através da junção provisória de duas ou mais posições, o que inclui a transformação dos elementos previamente estabelecidos em outras formações discursivas (Laclau e Mouffe, 1985, p. 105 e ss). Nunca se tratou de uma subsunção ou de uma assimilação de posições individuais em uma outra, mais abrangente, mas realizar acoplamentos e conexões exteriores entre elementos que, por sua vez, produzem uma totalidade distinta, desmontável, contingente e, por isso mesmo, sempre temporária.

Em sua obra Critical Environments, Cary Wolfe (1998) tratou de analisar certos traços teóricos advindos do pós-estruturalismo, da teoria dos sistemas, do pragmatismo norte-americano e de proponentes da virada linguística, como o segundo Wittgenstein, no tocante à epistemologia contemporânea. Um conceito transversal a cada uma dessas posições é o de exterior, que por vezes também se constitui em entorno ou meio ambiente, como no caso da teoria dos sistemas de Niklas Luhmann (Philippopoulos-Mihalopoulos, 2011, p. 45). Diversas são as menções feitas por Wolfe à teoria de Laclau e Mouffe, sobretudo na maneira como eles confrontam o fundamento ausente e opaco do social. Nesta passagem, por exemplo, a comparação com a teoria dos sistemas de Luhmann visa a ressaltar essa dimensão. Discorre Wolfe:

[...] a insistência da teoria do sistema no "ponto cego" constitutivo e na pluralidade de observações alimenta certa comparação com a teoria, de Ernesto Laclau, Chantal Mouffe e Slavoj Žižek, de um "antagonismo" irredutível oriundo do caráter "nãosuturado" do social. Esses teoristas, como Luhmann, não desconsideram ou 
reprimem aquilo que Žižek nomeia de a natureza "quebrada e pervertida" da comunicação, ao invés disso buscam derivar dela as condições de possibilidade para uma socialidade democrática. Assim como os teóricos do antagonismo social, Luhmann insiste que noções como "bloqueios", "impasses" ou aporias, tornam possível uma sociedade pluralista ao invés de impedi-la [...] (Wolfe, 1998, p. xvii) ${ }^{7}$.

Seguindo o paralelo desenvolvido por Wolfe, a existência do discurso estaria atrelada a uma redução de complexidade do seu entorno, o campo de discursividade, caracterizada através de sua própria delimitação perante o seu entorno. Dito de outro modo, toda formação discursiva não representaria mais do que uma modesta e restritiva possibilidade de significação do seu campo de discursividade. Se este campo é marcado por um excesso, o discurso passa a se caracterizar por uma redução de complexidade que vai lhe permitir uma manutenção relativa das suas fronteiras (Luhmann, 1989, p. 11 e ss).

O discurso, então, não existe tanto em função dos elementos que ele tende a incluir e que se encontram envolvidos pelas suas fronteiras, como também do que ele excluiu: o discurso não "enxerga" o espaço do mundo, somente podendo visualizar algo desde a sua perspectiva particular (Maturana e Varela, 1987, p. 23). Se Wolfe enfatiza a relação de antagonismo, assim o faz para ressaltar a delimitação de uma formação discursiva que, ao mesmo tempo em que mantida fora, precisa de algum modo ser internalizada. A diferenciação de uma formação hegemônica perante o seu entorno, ou seja, daquilo que ela não apreende, implica também em caracterizá-lo sempre a partir dos referenciais simbólicos estabelecidos pela perspectiva hegemônica, deixando-o assim de fora de suas operações específicas (Philippopoulos-Mihalopoulos, 2011, p. 47 e ss).

Em outras palavras, uma vez estabelecida a relação de antagonismo entre uma dada posição hegemônica e o seu exterior, contra-hegemônico, cada uma dessas formações vai introduzir a outra em sua narrativa sem, contudo, jamais apreendê-la em sua complexidade e distinção - e por isso o conceito de ponto cego (blind spots) é de grande relevância. O ponto cego não é aquilo que é percebido de outro modo, mas o que foge ao próprio campo de percepção de um referencial: existe, mas não pode ser apreendido por um dado observador (Foerster, 2003, p. 212 e ss).

O líder populista necessariamente precisa trazer para o seu discurso uma caracterização das forças sociais opostas às suas pretensões: os ricos, a elite parasitária, o sistema corrupto, etc. Todas essas expressões são descrições de um exterior que ocorrem através de uma perspectiva determinada e particular, por isso mesmo representando apenas mais uma possibilidade de produção de sentido em meio aos diversos segmentos do social (Laclau, 2005, p. 86 e ss). Em síntese, o líder populista constrói o seu próprio entorno, assim como os demais sistemas no âmbito das observações de segunda-ordem (Foerster, 2003, p. 212 e ss; Laclau e Mouffe, 1985, p. 139 e ss).

Se em Luhmann a produção de sentido passará por sistemas que se diferenciam funcionalmente, inclusive desenvolvendo um código binário que torna específica as suas operações no horizonte mais amplo do social, em Laclau a produção de sentido ocorre a partir dos sistemas discursivos (Luhmann,

\footnotetext{
${ }^{7}$ No original: "[...] systems theory's insistence on the constitutive "blind spot" and plurality of observation bears comparison with the theory, in Ernesto Laclau, Chantal Mouffe, and Slavoj Žižek, of an irreducible "antagonism" derived from the "nonsutured" character of the social. These theorists, like Luhmann, do not disavow or repress what Žižek calls the "broken and perverted" nature of communication, but instead attempt to derive from it the conditions of possibility for democratic sociality. Like the theorists of social antagonism, Luhmann insists that such "blockages", "deadlocks", or aporias do not impede but rather make possible a pluralist society [...]".
} 
1989, p. 36 e ss). Para Daniel de Mendonça e Léo Peixoto Rodrigues, o sistema discursivo não somente se caracteriza por uma dinâmica autorreferencial, como também emprega mecanismos de estabilização, mesmo que provisória, de fixação dos sentidos (Maturana e Varela, 1980, p. 98-99). $\mathrm{Na}$ teoria do discurso de Laclau e Mouffe, por exemplo, os pontos nodais desempenhariam essa função (Laclau e Mouffe, 1985, p. 139-140). Os autores destacam:

A produção de sentido para Ernesto Laclau, analogicamente à perspectiva de Luhmann, ocorre no interior do sistema discursivo, a qual defendemos aqui ser, a totalidade estrutural-relacional e autorreferenciada, resultado das práticas articulatórias. A prática articulatória entre momentos diferentes, por sua vez, é constituída por pontos nodais, que são, no interior da articulação, como já vimos, pontos discursivos privilegiados, uma vez que são capazes de realizar o próprio sentido do sistema discursivo, evitando assim o infinito deslizamento de significantes, no sentido de Lacan (Mendonça e Rodrigues, 2006, p. 96).

Assim como na teoria dos sistemas de Luhmann, o processo de diferenciação de um sistema discursivo, principalmente no que corresponde ao seu entorno (campo de discursividade), exige formas de estabilização e regularidade sem a qual a própria manutenção do sistema deixa de ser viável: sistema implica sempre delimitação, o que por sua vez leva a uma distinção entre o interno e o externo (Luhmann, 1989, p. 6 e ss; Laclau e Mouffe, 1985, p. 136 e ss; Rodrigues, 2006, p. 54 e ss). Ora, não sendo possível essa fixação, mesmo que precária e parcial, como no caso de uma formação hegemônica, então as noções de sistema e de hegemonia perdem o seu significado e relevância teórica (Laclau e Mouffe, 1985, p. 136 e ss). Ademais, Maturana e Varela elencam a fixação de fronteiras e limites como fundamentais para a emergência e a manutenção dos organismos vivos (Maturana e Varela, 1987, p. 39-40).

Se Laclau e Mouffe não abordaram diretamente temas caros à epistemologia, ou mesmo demonstraram qualquer interesse por esse campo, disso não se segue - e Wolfe sinaliza nessa direção - que as suas formulações não contemplem preocupações dessas áreas, principalmente no que diz respeito ao pós-fundacionismo sustentado pelos autores. Uma implicação possível e alinhada ao que pretenderam Maturana e Varela, chegando até Luhmann, reside na ideia de um fundamento autoestabelecido. A ideia de autoestabelecido encontra também certas ressonâncias em várias passagens dos escritos de Heidegger, muito embora ele não o faça a partir das preocupações teóricas aqui discutidas. Em Sobre a essência do fundamento, por exemplo, encontramos o seguinte trecho referente à noção de mundo $($ Welt $)$ :

O mundo é, enquanto a respectiva totalidade do em-vista-de de um ser-aí, posto por ele mesmo diante dele mesmo. Este pôr-diante-de-si-mesmo de mundo é o projeto originário das possibilidades do ser-aí, na medida em que em meio ao ente se deve poder comportar em face dele. O projeto de mundo, porém, é, da mesma maneira como não capta propriamente o projetado, também trans-(pro)-jeto do mundo projetado sobre o ente (Heidegger, 2005b, p. 136-137).

Se a hegemonia pretende suturar o universal e o particular, sempre falhando neste propósito, então é preciso investigar a própria noção da falha e a sua relação com o fundamento do social a ser 
discursivamente apreendido pela formação hegemônica. O primeiro passo para o esclarecimento dessa ideia reside em considerar a dinâmica de presença/ocultamente do fundamento, em termos de um processo contínuo de descrição e reconstrução das bases de uma certa estrutura de sentido, a exemplo de um sistema social. Em sua descrição dos sistemas autopoiéticos, Luhmann escreve:

Sistemas autopoiéticos, então, não são apenas sistemas que se auto-organizam, não apenas produzem e eventualmente mudam suas próprias estruturas; a sua autorreferência se aplica também à produção de outros componentes [...]. Deste modo, tudo que é utilizado como unidade pelo sistema é produzido enquanto unidade pelo próprio sistema. Isto se aplica a elementos, processos, fronteiras, outras estruturas e, por fim mas não menos importante, à unidade do próprio sistema [...]. Sistemas autopoiéticos, então, são soberanos com relação à constituição das identidades e diferenças (Luhmann, 1990, p. 3) ${ }^{8}$.

A diferenciação sistema/entorno implica contínuas redescrições do sistema em torno de si mesmo em virtude dos diversos estímulos externos que atuam sobre o próprio sistema. Por isso Marchart, no que concerne ao pós-fundacionismo, insiste na ideia de uma problematização incessante do fundamento que se coloca, não somente uma ausência que lhe retiraria também a sua função a partir de sua inserção em uma dada estrutura situada. Pensando esta questão através da linguagem da teoria dos sistemas, as redescrições são espécies de operação do sistema fechado de produção e reprodução circular de um sistema autorreferente (Luhmann, 2009, p. 143 e ss).

Se o campo de discursividade constitui o entorno de um sistema discursivo, o limite das suas operações, ou seja, aquilo que permite a sua operacionalidade em termos de produção de sentido e da criação de narrativas que organizam o social, repousa na relação de antagonismo. Considerando o antagonismo como o limite da objetividade, tal como dispõem Laclau e Mouffe em Hegemonia e Estratégia Socialista, o que se tem é uma reformulação contínua dos conteúdos particulares dos sistemas através da maneira como a relação antagônica vai ser posicionada e reajustada (Laclau e Mouffe, 1985, p. 122 e ss; Laclau, 1990, p. 17 e ss). Escrevem Daniel de Mendonça e Léo Peixoto Rodrigues:

Isso quer dizer que, em função do sistema discursivo estar disposto numa lógica relacional e antagônica com outros discursos, seus conteúdos particulares estão sempre alterando seus sentidos. Esse constante "alterar de sentido" provocado pela relação antagônica, impede a objetividade sistêmico-discursiva, ou seja, seu sentido finalístico ou objetivo é impossível (Mendonça e Rodrigues, 2006, p. 97).

O relacional é o que vincula as noções de sistema, antagonismo, exterioridade constitutiva e fundamento autoestabelecido (Laclau e Mouffe, 1985, p. 109 e ss; Laclau, 1990, p. 18 e ss). A relação de antagonismo não só permite a instauração de uma divisão entre interior (sistema

\footnotetext{
${ }^{8}$ No original: "Autopoietic systems, then, are not only self-organizing systems, they not only produce and eventually change their own structures; their self-reference applies to the production of other components as well [...]. Thus, everything that is used as a unit by the system is produced as a unit by the system itself. This applies to elements, processes, boundaries, and other structures and, last but not least, to the unity of the system itself [...]. Autopoietic systems, then, are sovereign with respect to the constitution of identities and differences".
} 
discursivo)/exterior (campo de discursividade), como modifica constantemente a relação entre esses dois polos: se o exterior de um sistema discursivo se modifica, essa modificação, por sua vez, será remetida ao próprio sistema discursivo para que ele, através de sua dinâmica interna específica, "responda" à modificação (Luhmann, 2002, p. 103 e ss; Laclau e Mouffe, 1985, p. 136-137). Ora, o próprio desenvolvimento dessa "resposta" traduz uma reação do sistema que implica na formulação de novos sentidos e da reorganização dos seus conteúdos internos a fim de se ajustar ao seu meio. Como bem observam Daniel de Mendonça e Léo Peixoto Rodrigues, é possível identificar um paralelismo entre as noções de antagonismo com a de irritação empregada por Luhmann (Mendonça e Rodrigues, 2006, p. 97 e ss; Laclau e Mouffe, 1985, p. 109 e ss).

Antagonismo e irritação apontam para a constituição relacional das operações do sistema, ou seja, a sua dinâmica interna está diretamente associada ao que ocorre em seu entorno, sendo também formas de responder ao que nele ocorre. Na medida em que cada resposta introduz no sistema transformações diversas, o que ilustra a reprodução das operações empreendidas pelo próprio sistema sobre si mesmo (Maturana e Varela, 1980, p. 100 e ss). O termo 'recursividade' tal como utilizado neste ponto indica a sucessão indefinida de operações que tomam como ponto de partida a operação precedente, transformando continuamente a estrutura na qual se encontram. Vejamos como isso ocorre a partir das noções de antagonismo e prática articulatória em Laclau e Mouffe.

Se o antagonismo proporciona a cisão pela qual as práticas articulatórias desenvolvem a sua organização, uma vez que a relação de antagonismo sofre alguma modificação, isso também afeta diretamente a composição das práticas articulatórias (Laclau e Mouffe, 1985, p. 136 e ss). Recapitulemos o seguinte ponto: a articulação é uma prática de conexão de elementos distintos que produz um outro elemento, diverso daqueles previamente conectados. É essa passagem que vai do isolamento caracterizado pela dispersão (o elemento) até a sua inserção em uma cadeia através da prática articulatória (momento diferencial), que proporciona a inserção do elemento na dinâmica autorreferencial do sistema.

Essa passagem, porém, só pode existir através da fixação de uma fronteira que divide o interno e o externo, o que ocorrerá mediante a relação de antagonismo. Sobre a relação entre prática articulatória e autorreferência sistêmica, Daniel de Mendonça e Léo Peixoto Rodrigues discorrem:

A prática articulatória agrega esses elementos transformando-os em momentos diferenciais. Portanto, um elemento ao ingressar na articulação, em relação a essa, deixa seu status de elemento e assume a condição de momento diferencial: passa, portanto, a fazer parte da autorreferência sistêmica (Mendonça e Rodrigues, 2006, p. 96).

Transformada a relação de antagonismo, responsável pela inserção de um referencial externo através do qual a prática articulatória vai se estruturar, as relações constitutivas da prática articulatória, e dos seus elementos, serão também transformados no transcorrer desse processo (Laclau, 1990, p. 18 e ss). Por isso a formação dos sistemas discursivos a partir de uma exterioridade: uma vez que os seus conteúdos são sempre determinados em termos relacionais através desse exterior, instaura-se uma dinâmica cíclica no qual ambos - sistema/entorno - são continuamente modificados através de suas interações. Essas modificações, porém, são operadas através dos próprios elementos que são constitutivos do sistema discursivo caso seja considerado um sistema fechado. 
O fundamento autoestabelecido, como defendemos, só pode ser provisório na medida em que seu estabelecimento - e conteúdo - tem como base sempre a diferenciação do sistema discursivo consigo mesmo. Se o que une Laclau/Mouffe e Luhmann, seguindo Daniel de Mendonça e Léo Peixoto Rodrigues (2006, p. 88), é que ambos desenvolvem também uma teoria da diferença, a noção de fundamento autoestabelecido serve, para além de apontar a dinâmica de presença/ocultamento oriunda da diferença ontológica, também um fio condutor para se pensar uma autopoiesis implícita na própria estrutura conceitual da teoria do discurso de Laclau/Mouffe.

Talvez uma investigação que persista neste caminho venha a agregar muito pouco em termos de estratégia política ou mesmo nos diversos debates sobre teoria e filosofia política que o próprio Laclau foi protagonista, é também importante considerar a maneira como a teoria do discurso interage com campos de investigação mais abrangentes e que operam na relação política/sociedade/ciência, a exemplo dos Estudos Sociais da Ciência e também da Teoria dos Sistemas.

Se investigações epistemológicas não foram prioritárias no desdobramento da teoria do discurso de Laclau/Mouffe, disso não se segue que ela esteja necessariamente afastada desse campo. As diversas pesquisas empíricas que recorreram ao aparato conceitual da teoria do discurso testemunham um crescente e significativo interesse em seu potencial analítico (Howarth, Norval e Stavrakakis, 2000). Se a teoria do discurso, com relação ao epistemológico e também ao metodológico, pode ser considerada "solta", cabe ao pesquisador, tendo como base o objeto de pesquisa e a circunstância na qual se encontra, organizar e reorganizar os conceitos e as premissas teóricas proporcionadas por Laclau/Mouffe.

A noção de fundamento autoestabelecido pode, talvez, mostrar-se significativa para aqueles que possuem interesse em observar como a construção da realidade circundante, seja ela material ou simbólica, é autoproduzida por sistemas discursivos. Uma das possibilidades analíticas reside, por exemplo, no mapeamento das sucessivas operações que desestruturam os sentidos previamente fixados pelo sistema discursivo, associando-os às transformações diversas que recaem sobre o seu entorno.

Compreendendo as implicações teóricas do fundamento autoestabelecido, o pesquisador pode ao menos compreender o caráter construtivista da teoria a que está recorrendo: o sentido da realidade não está aí para ser descoberto por conceitos como pontos nodais, cadeias de equivalência e práticas articulatórias, antes são essas noções mesmas que filtram, organizam e dispõem a realidade observada. Se toda descrição de uma dada realidade, seja ela social, econômica ou política, existe em função dos conceitos e das subsequentes formações discursivas nas quais o teórico se encontra investido e envolvido, um ponto privilegiado, transcendental, com o qual se pode criticar e confrontar um determinado arranjo social já não encontra acolhimento nesta abordagem teórica.

Disso não se segue que as distintas formas de construção da realidade, o que inclui as categorias empregadas pelos teóricos, sejam isentas do escrutínio crítico. Laclau e Mouffe, especialmente em Hegemonia e Estratégia Socialista, em muito questionaram certas categorias centrais para a teoria marxista, a exemplo de classe social.

\section{Considerações Finais}

O objetivo deste artigo foi desenvolver algumas das implicações da diferença ontológica, inicialmente formulada por Heidegger, na teoria do discurso de Laclau e Mouffe, tendo como principal referência 
o pós-fundacionismo dos autores. Com isso se esperou lançar as bases para uma reconsideração do fundamento em termos de auto estabelecimento, ou seja, de um fundamento que é desenvolvido pela própria estrutura/sistema no qual se inscreve. Deste modo, a autorreferencialidade do sistema discursivo, tal como Daniel de Mendonça e Léo Peixoto Rodrigues o concebem, pode ser explicitada de forma a ressaltar a maneira como um objeto é construído pelos conceitos empregados pelo pesquisador. Isso não significa, porém, abrir mão de uma atitude crítica com relação às diversas maneiras pelas quais o objeto é construído. Ao longo de Hegemonia e Estratégia Socialista, por exemplo, o conceito de classe social como elemento explicativo da ordem social e também de sua transformação é diretamente criticado pelos autores.

Para além do esclarecimento da diferença ontológica, o passo seguinte fora o de esclarecer uma noção bastante recorrente nos trabalhos de Laclau e Mouffe, a saber, a exterioridade constitutiva. Neste trabalho, a exterioridade constitutiva é duplamente relativa por dois sentidos: primeiro, sublinha o caráter relacional existente entre o sistema discursivo e o seu entorno, o campo de discursividade; segundo, permite observar o fechamento operacional do sistema discursivo na medida em que precisa simultaneamente descrever este exterior através dos seus termos, mas excluí-lo de sua dinâmica interna. Em função de sua relação constitutiva com o exterior, o sistema discursivo está sempre reinterpretando e se reorganizando em função das respostas que precisa fornecer aos estímulos advindos do exterior. A apreensão do exterior pelo sistema é sempre parcialmente realizada, indefinida e, por isso mesmo, incompleta. Uma totalidade, sem dúvida, mas cindida, aberta, instável.

Em síntese, seguindo as considerações de Daniel de Mendonça e Léo Peixoto Rodrigues sobre esta questão, a distinção discurso/campo de discursividade submete o discurso a uma contínua redescrição desenvolvida a partir das suas operações internas. A exterioridade do discurso é internalizada através de sua exclusão que, por sua vez, ocorre através dos elementos constitutivos daquela mesma formação discursiva.

$\mathrm{Na}$ terceira e última seção deste artigo, a problemática do pós-fundacionismo é associada às teorizações epistemológicas contemporâneas, principalmente os conceitos fornecidos por Maturana, Varela e Luhmann. Muito embora as pretensões da teoria do discurso estejam definitivamente inseridas no domínio da ontologia, várias das suas premissas e linhas de argumentação possuem implicações epistemológicas significativas. A comparação entre as abordagens teóricas mencionadas serviu para ressaltá-las. Esta última seção tem em seu cerne uma reconsideração do fundamento em termos de uma auto fundamentação, ou fundamento auto estabelecido, que está continuamente sendo questionada e reestabelecida.

Uma das implicações práticas do desdobramento teórico é ressaltar como os conceitos da teoria do discurso, a exemplo de práticas articulatórias, hegemonia, cadeias de equivalência, dentre outros, organizam e atribuem sentido à realidade exterior ao invés de serem elementos a ser identificados naquilo que se observa. Se o fundamento de um sistema discursivo é estabelecido por ele mesmo, segue-se que todas as descrições feitas de uma realidade exterior são, na verdade, descrições formadas a partir dos conceitos elencados, ou seja, são autodescrições.

A partir da aproximação que se faz com a teoria dos sistemas, o fechamento do sistema discursivo e a sua consequente autoprodução, pensada neste ponto em termos construtivistas, podem constituir referenciais para que o pesquisador observe também como a maneira com que ele aborda a teoria do discurso ou que analisa uma certa configuração política são construções desenvolvidas a partir das suas opções teóricas e conceituais. Cadeias de articulação e pontos nodais representam já 
construções que operam sobre a descrição de uma dada realidade ao invés de elementos que a constituem e, por isso mesmo, precisariam ser encontrados pelo pesquisador.

\section{Referências}

ARENDT, Hannah. A Condição Humana. Rio de Janeiro: Ed. Forense Universitária, 2016.

DERRIDA, Jacques. Structure, Sign, and Play in the Discourse of Human Sciences. In: DERRIDA, Jacques. Writing and Difference. Chicago: Chicago University Press, 1978.

FOERSTER, Heinz Von. Understanding Understanding: Essays on Cybernetics and Cognition. New York: Springer, 2003.

HEGEL, Georg Wilhelm Friedrich. Fenomenologia do Espírito. Petrópolis: Editora Vozes, 2003.

HEIDEGGER, Martin. Ser e Tempo (Parte 1). Petrópolis: Editora Vozes, 2005a.

. Sobre a Essência do Fundamento. In: STEIN, Ernildo (Org). Martin Heidegger:

Conferências e Escritos Filosóficos. São Paulo: Nova Cultural, 2005 b.

HOWART, David; NORVAL, Aletta J.; STAVRAKAKIS, Yannis. Discourse Theory and Political Analysis: Identities, Hegemonies and Social Change. Manchester: Manchester University Press, 2000.

LACLAU, Ernesto. On Populist Reason. London: Verso, 2005.

. Structure, History and the Political. In: BUTLER, Judith; LACLAU, Ernesto; ŽIŽEK, Slavoj. Contingency, Hegemony, Universality: Contemporary Dialogues on the Left. London: Verso, 2000.

. Emancipation(s). London: Verso, 1996. pp. 20-35.

. The Making of Political Identities. London: Verso, 1994

. New Reflections on The Revolution of Our Time. London: Verso, 1990.

LACLAU, Ernesto; MOUFFE, Chantal. Hegemony and Socialist Strategy: Towards a Radical Democratic Politics. London: Verso, 1985.

LACLAU, Ernesto; ZAC, Lilian. Minding the Gap: The Subject of Politics. In: LACLAU, Ernesto (Ed.). The Making of Political Identities. London: Verso, 1994.

LUHMANN, Niklas. Self-Organization and Autopoiesis. In: CLARKE, Bruce; HANSEN, Mark B. N. (Orgs). Emergence and Embodiment: New Essays on Second-Order Systems Theory. Durham: Duke University Press, 2009.

. Theories of Distinction: Redescribing the Descriptions of Modernity. Stanford: Stanford University Press, 2002.

. Autopoiesis of Social Systems. In: LUHMANN, Niklas. Essays on Self-Reference. New York: Columbia University Press, 1990.

. Ecological Communication. Chicago: University of Chicago Press, 1989.

MARCHART, Oliver. Post-Foundational Political Thought: Political Difference in Nancy, Lefort, Badiou and Laclau. Edinburgh: Edinburgh University Press, 2007. 
MATURANA, Humberto R.; VARELA, Francisco J. The Tree of Knowledge: The Biological Roots of Human Understanding. Boston: Shambhala, 1987.

. Autopoiesis and Cognition: The Realization of the Living. London: D. Reidel Publishing, 1980.

MENDONÇA, Daniel de; RODRIGUES, Léo Peixoto. Laclau e Luhmann: um diálogo possível. In: MENDONÇA, Daniel de; RODRIGUES, Léo Peixoto (Orgs). Ernesto Laclau \& Niklas Luhmann: pós-fundacionismo, abordagem sistêmica e organizações sociais. Porto Alegre: EDIPUCRS, 2006.

MOUFFE, Chantal. On the Political. London: Verso, 2005.

. The Return of the Political. London: Verso, 1993.

PHILIPPOPOULOS-MIHALOPOULOS, Andreas. Critical Autopoiesis: The Environment of the Law. In: VRIES, Bald de; FRANCOT, Lyana (Orgs). Law's Environment: Critical Legal Perspectives. The Hague: Eleven International Publishing, 2011.

RODRIGUES, Léo Peixoto. A (des)estruturação das estruturas e a (re)estruturação dos sistemas: uma revisão epistemológica crítica. In: MENDONÇA, Daniel de; RODRIGUES, Léo Peixoto (Orgs). Ernesto Laclau \& Niklas Luhmann: pós-fundacionismo, abordagem sistêmica e organizações sociais. Porto Alegre: EDIPUCRS, 2006.

WOLFE, Cary. Critical Environments: Postmodern Theory and the Pragmatics of the "Outside". Minneapolis: University of Minnesota Press, 1998.

Artigo recebido em: Junho/2019

Artigo aprovado em: Novembro/2019

Leonardo Monteiro Crespo de Almeida (leonardoalmeida326@gmail.com) é professor substituto da Faculdade de Direito do Recife da Universidade Federal de Pernambuco (UFPE) e professor da Faculdade Imaculada Conceição do Recife (FICR). Doutor em Direito pela Universidade Federal de Pernambuco (UFPE).

\section{Diferença Ontológica, Pós-Fundacionismo e Exterioridade Constitutiva: reflexões sobre o fundamento autoestabelecido na Teoria do Discurso de Ernesto Laclau e Chantal Mouffe}

Resumo. O presente artigo busca associar três noções - diferença ontológica, pós-fundacionismo e exterioridade constitutiva - para repensar o sentido do fundamento na teoria do discurso de Ernesto Laclau e Chantal Mouffe. O objetivo reside em desenvolver a noção de fundamento autoestabelecido, noção que visa a destacar a maneira como as formações discursivas teorizadas por Laclau e Mouffe tendem a operar como sistemas fechados que produzem e descrevem o seu entorno através de suas próprias operações. Através de uma justaposição entre a teoria do discurso e a teoria dos sistemas de Niklas Luhmann, o artigo reforça a maneira como os sistemas discursivos constroem e são construídos em interação com o seu exterior, reorganizando continuamente os seus elementos e, com isso, as descrições que fazem do seu exterior. Um fundamento autoestabelecido, portanto, reitera a dinâmica circular e diferencial presente na relação entre um sistema discursivo e o seu exterior. 
Através de um desenvolvimento estritamente ontológico, o pós-fundacionismo, este artigo tenta desenvolver também as implicações epistemológicas da teoria do discurso em termos construtivistas. Palavras-chave: Laclau; Luhmann; Teoria do Discurso.

\title{
Ontological Difference, Post-Foundationism and Constitutive Exteriority: remarks on the self-posited ground within Ernesto Laclau and Chantal Mouffe's Discourse Theory
}

\begin{abstract}
This present article intends to connect three notions - ontological difference, postfundacionism, constitutive exteriority - in order to rethink the meaning of ground within Ernesto Laclau and Chantal Mouffe's discourse theory. The objective is to clarify the notion of selfestablished ground, a notion that would expose how the discursive formations that are theorized by Laclau and Mouffe operate as closed systems that product and describes their environment through their own operations. By juxtaposing discourse theory and the system theory of Niklas Luhmann, this research shows and reinforces how discursive systems construct and are constructed through successive interactions with their exterior, continually self-organizing their elements e their descriptions of their environment. A self-established ground exposes the circular and differential dynamics that are constitutive of the relation between a discursive system and their exterior. Through a strictly ontological starting point - post-fundacionism -, this article tries to develop the epistemological consequences of discourse theory appealing to a strictly constructivist approach.
\end{abstract}

Keywords: Laclau; Luhmann; Discourse Theory. 